Revue d'histoire du XIXe siècle

Société d'histoire de la révolution de 1848 et des

révolutions du XIXe siècle

Religion, politique et culture au XIXe siècle

\title{
Karine Salomé, Les Îles bretonnes. Une image en construction (1750-1914), Rennes, Presses universitaires de Rennes, $472 \mathrm{p}$.
}

\section{Vincent Guigueno}

\section{OpenEdition}

\section{Journals}

Édition électronique

URL : http://journals.openedition.org/rh19/639

DOI : 10.4000/rh19.639

ISSN : $1777-5329$

Éditeur

La Société de 1848

Édition imprimée

Date de publication : 1 juin 2004

Pagination : 194-195

ISSN : 1265-1354

\section{Référence électronique}

Vincent Guigueno, « Karine Salomé, Les Îles bretonnes. Une image en construction (1750-1914), Rennes, Presses universitaires de Rennes, 472 p. », Revue d'histoire du XIXe siècle [En ligne], 28 | 2004, mis en ligne le 19 juin 2005, consulté le 22 septembre 2020. URL : http://journals.openedition.org/rh19/639 DOI : https://doi.org/10.4000/rh19.639

Ce document a été généré automatiquement le 22 septembre 2020

Tous droits réservés 


\title{
Karine Salomé, Les Îles bretonnes. Une image en construction (1750-1914), Rennes, Presses universitaires de Rennes, $472 \mathrm{p}$.
}

\author{
Vincent Guigueno
}

Des îles sans histoire?

2 Fraîchement sorti de l'École des Ponts et Chaussées dans les années 1830, l'ingénieur Auguste Mille, est affecté à la construction du grand phare de Sein. Dans la correspondance qu'il entretient avec sa hiérarchie parisienne, voici la description qu'il fait de son séjour insulaire : «Depuis deux ans, écrit-il, j'habite sur le triste et stérile rocher de l'île de Sein; depuis deux ans, je n'ai connu qu'une vie de dangers et de privations, logé dans une mauvaise baraque, nourri comme un pêcheur, livré à la mer comme un matelot». Les îles bretonnes sont aujourd'hui des lieux de villégiature recherchés dont l'image est très éloignée de la description proposée par Mille. Quelques décennies plus tard, la visite au phare s'impose comme une étape incontournable du parcours touristique, où l'on vient contempler l'île "comme un raccourci de carte géographique » (p. 155).

3 L'ouvrage de Karine Salomé raconte comment les appréciations portées sur ces espaces réputés singuliers se transforment positivement au fil du temps. Façonnés par le regard des agents du pouvoir - hydrographes, ingénieurs, administrateurs - à la fin du XVIII ${ }^{\mathrm{e}}$ siècle, les paysages des îles font le bonheur des savants, des artistes, puis des touristes qui les fréquentent assidûment dès que des lignes de transport ferroviaires et maritimes se mettent en place. Fidèle à la grille de lecture proposée par Alain Corbin dans son Territoire du vide (1988), Salomé brosse un tableau tout en nuances de la sédimentation de ces représentations, analysant de nombreux, récits anonymes ou connus, comme le voyage de l'administrateur Jacques Cambry à Ouessant en l'an III, ou bien l'escapade de Gustave Flaubert et Maxime Du Camp vers Belle île en 1840. 
4 Le voyage proposé au lecteur est plaisant et ouvre de nombreuses pistes de réflexion qui peuvent être prolongées jusqu'au temps présent. Les sources examinées, en particulier les guides de voyage, montrent bien comment se construit une solidarité territoriale et culturelle entre les îles bretonnes qui culminera avec la constitution, dans les années 1970, d'une association des « îles du Ponant» dont le nom archaïsant devait sans doute masquer les origines technocratiques. Alors qu'elles s'inscrivent dans des espaces géographiques divers, construits par des pratiques économiques et sociales qui n'ont pas grand chose en commun, sinon une vague "maritimité ", le touriste et l'artiste enferment l'île dans un isolat communautaire que les savants avaient jugé digne d'intérêt pour l'ethnologue. On est loin du regard de l'ingénieur des fortifications, venu jauger les capacités de défense de ces forteresses d'une frontière nationale en construction. L'histoire que Karine Salomé nous raconte est la conversion de cette frontière en "limite »: un espace sans histoire, à l'écart des conflits et des tensions que l'on vient fuir. Les îles bretonnes deviennent des espaces refuges, des utopies pour les touristes modernes qui laissent leur automobile à l'embarcadère du bateau.

5 Si le processus de ségrégation qui construit cette illusion est bien décrit, il est plus difficile de saisir comment des communautés de plus en plus exposées au regard des autres y réagissent. L'insulaire, relégué au rang de figurant, est en effet l'absent du paysage. Le bouleversement de ces micro-sociétés sous les effets conjugués des arts, du tourisme, mais aussi de la grande presse, qui contribue à populariser l'image d'un insulaire farouche mais courageux - le supposé naufrageur devenu sauveteur - n'est pas développé, faute de sources nous dit Karine Salomé. Quand celles-ci sont exhumées, leur analyse fait d'ailleurs penser aux écrits des voyageurs que l'historienne étudie. Les archives judiciaires permettent ainsi de dire qu' « à travers les situations de conflits, les petits délits et les micro événements qui se déroulent dans les îles, se font jour des sociétés organisées autour de principes et de valeurs, de règles et de modes de gestion qui pour beaucoup restent empreints d'imprécision" (p. 405). On regrette que le modèle des relations entre visiteurs et insulaires ne soit plus étoffé, en appliquant un principe de symétrie qui prendrait au sérieux l'existence d'un regard de l'insulaire sur le savant, l'artiste ou le touriste.

On peut enfin se demander si le travail de l'historienne ne participe pas de la reproduction du stéréotype insulaire dont il étudie la genèse. Une introduction plus réflexive aurait pu interroger les enjeux d'une histoire des îles bretonnes alors que celles-ci vivent aujourd'hui une mutation foncière et sociologique encouragée par leur image, construite sur la longue durée : l'installation de néo-insulaires urbains, sur fond de spéculations immobilières intenses, favorisées par des politiques publiques de défense du patrimoine et de l'environnement. 